\title{
O caso do frei Manuel da Madre de Deus notas sobre um processo eclesiástico na Bahia do século XVIII
}

\author{
Father Manuel da Madre \\ de Deus' case
}

notes on an ecclesiastic process in XVIII century, Bahia/Brazil

\author{
ROBERTO DA SILVA RIBEIRO \\ Doutor pela UFPE \\ Arqueólogo do IPHAN, Superintendência de Sergipe. \\ Travessa Baltazar de Góes, n. 86-14ªndar \\ Aracaju, Sergipe \\ roberto.8sr@iphan.gov.br
}

RESUMO Frei Manuel da Madre de Deus Bulhões nasceu em Salvador, em 1673 e morreu em data posterior a 1742. Foi procurador geral do Carmo em Lisboa e vigário geral da Vigaria do Carmo da Bahia e Pernambuco. Em 1727 é acusado de diversos crimes. Foi o caso julgado a pedido do visitador geral de Lisboa, em primeira instância no convento carmelita da Bahia. Foi frei Manuel acusado de viver em concubinato com a viúva Helena de Lima, violar o voto de pobreza ao obter lucros com um engenho na ilha das Fontes e mandar matar Manuel Guedes de Brito e seu escravo. Frei Manuel foge de seu convento e entra com recursos contra a condenação. Em 1739 é absolvido e é reinvestido de suas prerrogativas.

* Artigo recebido em: 25/08/2008. Aprovado em: 07/06/2009. 
Palavras-chave Brasil colônia, Ordem do Carmo, Bahia colonial, Coroa portuguesa, Igreja Católica

ABSTRACT Father Manuel da Madre de Deus Bulhões was born in Salvador, Brazil, in 1673 and dead after 1742. He was general procurator of Carmel Order in Lisbon and general father of Vigaria of Carmel on Bahia and Pernambuco. In 1727 he was accused of several crimes. The case was judged by petition of general visitator of Lisbon, on first instance on Carmel's convent of Bahia. Father Manuel was accused to live in concubinate with the widow Helena de Lima, to abandon the vow of poverty when he obtained profits with a engenho on I/ha das Fontes and to kill Manuel Guedes de Brito and his slave. Father Manuel runway from his convent and applied against his condemnation. In 1739 he was absolved and got again his prerogatives.

Keywords colonial Brazil, Carmel order, colonial Bahia, Portuguese crown, Catholic Church.

\section{Introdução}

Comumente se diz que a História estuda o passado para compreender o presente. Paradoxalmente a História não pode ser uma ciência sobre o passado, pois este não mais existe, porém uma ciência que analisa os vestígios do passado que existem no presente.

Documentos são vivificantes para a História, são eles que nos trazem nomes e pensamentos, fazendo com que categorias descarnadas tomem corpo e sangue. Os documentos, porém, dão a falsa impressão de se estar estudando, realmente, o passado, e não um texto, um discurso. Tal ilusão dominou a História durante muito tempo e o historiador demorou a se ver como um analista do texto, ou de um discurso sobre o passado.

O objetivo deste trabalho é fazer uma análise preliminar do processo criminal que sofreu Frei Manuel da Madre de Deus Bulhões, acusado de mandante de assassinato e violador dos votos de castidade e pobreza tendo como base o transcrito no Livro Primeiro de Actas da Província Carmelita da Bahia. Nossa principal fonte, o Livro Primeiro de Actas da Província Carmelita da Bahia ${ }^{1}$ (1720 a 1780) é um in folio de 398 páginas numeradas a maior parte em Latim, com algumas poucas páginas em português e em italiano. O livro se acha arquivado no Arquivo da Ordem Carmelita, abrigado na Paróquia Nossa Senhora do Carmo de Belo Horizonte.

1 Belo Horizonte. Arquivo da Paróquia Nossa Senhora do Carmo. Livro Primeiro de Actas da Província Carmelita da Bahia Citado simplesmente como Actas seguido pelo número das páginas. 
O problema metodológico está na confiabilidade de uma única fonte para a análise da ação. Apesar de as Actas transcreverem peças do processo jurídico civil, não se pode confiar na sua fidelidade e nem sequer pô-la em xeque. Simplesmente não conhecemos as peças do processo por outras fontes. Assim temos uma única fonte sobre o caso.

Se estivéssemos buscando "a verdade" sobre o que aconteceu, este seria um problema insolúvel, entretanto, assumindo que estamos buscando "indícios", como diz Carlo Ginzburg, ${ }^{2}$ para sobre eles construir um discurso sobre eles, o problema metodológico do documento único é superado, pelo menos neste sentido.

As formas ritualizadas e lacônicas dos documentos eclesiásticos registrados (atas) ou transcritos nesse livro não permitiram o registro exato das ações e reações exaltadas, entrevistas nos textos expurgados pelo secretário latino da congregação. Mesmo assim, percebe-se que as pequenas perturbações na ordem canônica em que os atos deveriam acontecer, a falta de polidez de certas atitudes e expressões registradas e o inopinado de certas alterações nas fórmulas refletem um acalorado debate e de uma conduta pouco decorosa para frades de tão antiga ordem religiosa.

\section{Frei Manuel}

O carmelita frei Manuel da Madre de Deus Bulhões, doutor em teologia, nasceu em Salvador, em 1673 e morreu em data posterior a 1742, apesar de Marina Massimi indicar para a morte a data de 1737. ${ }^{3}$ Nesta data, o frei ainda aparecia nas atas de seu convento, em 1742 é feita a última menção a sua pessoa nas ditas atas. Em 1699 fora procurador geral do Carmo em Lisboa e, entre 1701 e 1706, foi vigário geral da Vigaria do Carmo da Bahia e Pernambuco, antes que esta fosse elevada à Província.

Frei Manuel é hoje lembrado por raros eruditos por seus sermões pregados em Lisboa e Salvador, e por um soneto que Ihe dedicou Gregório de Matos Guerra:

Ao sermão da Justiça que pregou

Frei Manuel da Madre de Deus na Igreja do Carmo, no ano de 1686.

Alto sermão, egrégio, e soberano

Em forma tão civil, tão erudita,

Que sendo o pregador um carmelita,

Julguei eu, que pregava um Ulpiano.

2 GINZBURG, Carlo. Mitos, emblemas, sinais. 2a ${ }^{\mathrm{a}}$.ed. São Paulo: Companhia das Letras, 2007.

3 MASSIMI, Marina. Um importante corpo documentário para a reconstrução da história da cultura no Brasil colonial: Os acervos da oratória sagrada. Memorandum- Memória e História em Psicologia, Belo Horizonte, v.10, p.45-64, 2006. . (acesso em 27/11/2007). 
Não desfez Alexandre o nó Gordiano,

Co'a espada o rompeu (traça esquisita)

Soltais na forma legal, e requisita

Soltais o nó do magistrado arcano.

Ó Príncipes, Pontífices, Monarcas,

Se o Mestre excede a Bártolos, e Abades

Vesti-Ihe a toga, despojai-Ihe alparcas.

Rompam-se logo as leis das Majestades,

Ouçam Ministros sempre os Patriarcas,

Pois mais podem, que leis, autoridades.

Porém sua vida foi atribulada e marca um dos casos muito interessante da vida monástica da capital do Brasil colonial.

\section{A província}

Os carmelitas chegaram ao Brasil no século XVI e até o século XVIII estavam subordinados à província carmelita de Lisboa. ${ }^{4}$

Em 1685 foi pedida a criação da província carmelita da Bahia e Pernambuco pelo prior geral do Carmo. Em 1686, esta foi criada junto da província do Rio de Janeiro pelo Papa Clemente XI, em 1687, foi emitido o breve confirmando a separação das províncias, publicado em 1720, e em 1722 foi instalada a nova província.

A província carmelita da Bahia e Pernambuco, contava com os conventos de Cachoeira e Salvador, na Bahia; de Sergipe del Rei e de Olinda, em Pernambuco. Além dos conventos, também havia vários hospícios (pequenos conventos sem autonomia) e casas de missões indígenas. Também o convento da Paraíba pertencia à Província, porém este era ocupado por irmãos reformados, que não aceitavam a autoridade dos regulares. Durante o tempo em que durou a província de Pernambuco e Bahia, durou a querela entre os regulares e os reformados.

Segundo o breve Quoniam totius decoris que criou a província carmelita da Bahia e Pernambuco, muitos frades no Brasil, distantes das autoridades eclesiásticas e espalhados pelo vasto território da colônia nutriam costumes imorais, sendo desrespeitosos e insolentes para com seus superiores, sem que houvesse como os punir, pois fugiam de um convento para outro, aproveitando-se da rivalidade entre as ordens. Assim, a criação das províncias carmelitas do Rio de Janeiro e da Bahia e Pernambuco, foi uma

4 MOLINA, Sandra Rita. Na dança dos altares: a ordem do Carmo e a irmandade da Boa Morte entre o poder e a sobrevivência no Rio de Janeiro dos primeiros anos do Império (1814-1826). Revista História, São Paulo, USP, p.112, 2002. 
tentativa de se estabelecer a disciplina entre os padres dessa ordem. ${ }^{5}$ Este breve é citado na integra várias vezes nas Actas quando há, no entender do prior do momento, grave crise na disciplina conventual.

A província era regida por um padre provincial e por um grupo chamado capítulo definitório, cujos membros eram chamados "definidores". Existiam dois tipos de definidores, os que eram eleitos pelo "grêmio", uma assembléia dos irmãos mais graduados (os "gremiais"), e os que eram definidores "perpétuos", por direito próprio, ou por nomeação de alguma autoridade superior. De três em três anos, se reunia o grêmio para eleger seus representantes e para resolver questões que isso exigia, todos os anos, na terceira semana depois da Páscoa, se reunia o definitório para deliberar sobre coisas de sua competência. Dentro do grêmio, havia diversos graus e funções: mestres, presentados, sacristães, sócios, secretários, etc.

\section{O caso}

Manuel da Madre de Deus, doutor em Teologia, ex-vigário provincial da Vigaria Carmelita da Bahia e Pernambuco, definidor perpétuo da província por direito próprio, havia levado uma vida normal e exitosa para um frade de sua ordem até que em 1727 é acusado de diversos crimes. Foi o caso julgado a pedido do reverendo padre presentado Boaventura da Conceição, visitador geral de Lisboa, em primeira instância no convento carmelita da Bahia. O visitador geral era um representante do rei que tinha como função manter a ordem com respeito aos religiosos, que eram encarados como funcionários do estado.

Foi frei Manuel acusado de viver em concubinato com a viúva Helena de Lima, em uma casa que mantinha fora do convento, de violar o voto de pobreza ao obter lucros com um engenho seu na ilha das Fontes e de mandar matar Manuel Guedes de Brito e seu escravo Salvador. Em 1730 é condenado pela justiça eclesiástica a ser excluído do grêmio de sua província e ser recolhido à prisão perpétua no convento de Sergipe del Rei a pão e água às segundas, quartas e sextas. O julgamento pelo prior da Bahia, Francisco Xavier de Santa Teresa, e frei Maurício do Sacramento havia sido a favor de ampla absolvição do réu. A ata da sessão do capítulo em que foi debatido o relatório do julgamento está rasurada. ${ }^{6}$ Nota-se, porém que as principais discussões foram a respeito da competência do prior do convento da Bahia em julgar o caso. Será preciso esperar pelas atas de 1739 para conhecer os detalhes da acusação e da condenação. Também se nota que a ata do julgamento não foi apresentada, pois havia sido tirada do lugar e escondida em lugar desconhecido. Quando o visitador geral no-

5 Actas, p.27-28.

6 Actas, p.100. 
meado por Lisboa, frei Boaventura da Conceição manda buscar o acusado, ele foge. Então "quibus exponitis et mature perpensis statuit Definitorium, nemine discrepante, standum non esse pro sententia absolvente dictum P. M. Emmanuele a Matre Dei". ${ }^{7}$

O provincial Francisco de Santa Teresa, diante da decisão do definitório, condena frei Manuel. Sendo a condenação proferida pela província, a sentença deveria ser ratificada pelo prior geral da Ordem, Gaspar Pizzolanti, na Itália, mas, por causa das distâncias, a sentença passaria a vigorar ad referendum. Por isso frei Manuel fugiu, se colocando sob a proteção do prior dos beneditinos e os advogados do acusado recorreram ao prior geral e à justiça comum, como saberemos depois.

\section{Frei Boaventura da Conceição}

Como se pode notar, Boaventura da Conceição teve um papel ativo na condenação de Manuel da Madre de Deus. Em 21 de abril de 1722, durante a $6^{a}$ sessão da reunião capitular, Boaventura aparece nas atas da província ao ser eleito sacristão-mor do convento da Bahia. Este não deixava de ser um cargo importante, pois auferia rendas de missas e cerimônias praticadas para os leigos e tinha um caixa próprio que emprestava dinheiro a juros ao convento. Em 1724, Frei Agostinho de Santa Ana morreu, sendo substituído como sócio capitular (uma espécie de suplente) por Boaventura da Conceição. Em 22 de abril do ano seguinte, Boaventura da Conceição obteve o importante cargo de prior do convento de Cachoeira, o segundo mais importante da Bahia e um dos três mais importantes de toda a província eclesiástica.

É em 1727 que Boaventura é nomeado pelo prior de Lisboa como visitador para o $3^{\circ}$ ano de visitação, o que lhe daria poderes de corregedor sobre sua ordem no nordeste do Brasil. Neste mesmo ano, ele consegue a patente de presentado extranumerário de púlpito, o que lhe garantiria, além de uma renda extra, a presença no capítulo com poderes decisórios.

Embora não conste nas atas, deve ter sido em seu período como visitador que se iniciaram as investigações contra Manuel da Madre de Deus e, como vimos, foi graças a seu empenho que frei Manuel foi condenado pelo definitório. Os motivos exatos deste empenho - se motivos pessoais, se desejo de afastar alguém que o impedia de subir na hierarquia eclesiástica, se sentimento de justiça - é impossível de averiguar. Entretanto, o afastamento de Madre de Deus contribuiu para o enfraquecimento da camarilha que o apoiava abrindo alas para a ascensão de frei Boaventura e de seu "partido" na hierarquia conventual.

7 "Pelo exposto e maduramente meditando, estabeleceu o Definitório, sem ninguém discordar, não ser a favor da sentença que absolve o dito Padre Mestre Manuel da Madre de Deus". 
No mesmo ano da condenação e da fuga de Frei Manuel, 1730, frei Boaventura é nomeado prior do convento de Sergipe em São Cristóvão. Não esqueçamos que se Madre de Deus não tivesse fugido, ficaria preso no convento de São Cristóvão, a pão e água, a partir de 1730. Este evento indica talvez um desejo de Conceição em se tornar carcereiro de seu confrade, o que é um indício de uma vendeta pessoal no caso.

Em 26 de abril de 1733, frei Boaventura da Conceição atinge o ápice da sua carreira, começada havia 11 anos, ao ser eleito prior da Bahia. Neste mesmo ano, obtém de Roma ainda a patente de mestre de púlpito e justiça, a mais ambicionada pelos irmãos de sua ordem. Frei Boaventura logo começou a perceber que o cargo de prior não era só cheio de glórias, mas trazia suas dificuldades. Já em 17 de maio de 1734, durante a $4^{a}$ sessão da $1^{a}$ congregação intermediária, diante do provincial, depois das cerimônias de praxe,

R. P. Magister Bonaventura a Conceytione (sic) 2us Definitor, ac hujus Conventus Prior, habita a R. Adm. P. M. Provinciali Praesidi venia, exposuit, quod Prioribus ejusdem Conventus valde onerosa erat obligatio celebrandi Missam ex intensione Communitatis, propter insanum, indefessumque laborem eorundem Priorum, máxime in acquirendis pecuniis pro sustentationem Fratrum; nam cum omnes fere Conventus Brasiliensis certis et determinantis redditibus pro sumptibus necessariis careant, descundant graviter Priores, modo in ambiendis proventis quos substentationi subditorum solent, modo in curandis, et procurandis litibus, quorum Decimae in hisce regionibus sunt inextinguibiles; modo deninque in visendis, et invinsendis communibus grangiis quapropter suplicarit pro absolutioni supradictae obligationis, sibi et caeteris Prioribus in posterum vel in praemium, vel in laborum levamen. ${ }^{8}$

Claro que Boaventura poderia estar apenas ecoando a opinião dos outros priores como meio de obter certa liderança, pois com poucos meses de priorado, estas dificuldades não seriam já tão notáveis, não houve grandes dificuldades para frei Boaventura até 1736, quando frei Manuel volta ao convento protegido por uma liminar da justiça régia.

\section{A volta de frei Manuel}

Nos anos em que esperava o julgamento do recurso, Manuel viveu no mosteiro dos beneditinos, o que the serviu de atenuante, pois continuara

8 "o Reverendo Padre Mestre Boaventura da Conceição, $2^{\circ}$ Definidor e Prior deste convento, obteve vênia do Reverendo Administrador Padre Mestre Provincial Presidente e expôs que aos Priores deste convento era muito onerosa a obrigação de celebrar missa em intenção da comunidade por causa da doença e do incansável trabaIho destes Priores, máxime no adquirir dinheiro para a sustentação dos irmãos; com efeito, quando quase todos os conventos brasileiros carecem de rendas certas e determinadas para os gastos necessários, fazem suar os priores, ora a caçar proventos para a sustentação dos subordinados, ora a cuidar e procurar dos litígios sobre o Dízimo, que nessas regiões são inextinguíveis, ora, enfim, de modo digno e indigno nas granjas comuns. Pelo que suplicou pela dispensa das supraditas obrigações para si e para os outros Priores". Actas, p.148-149. 
sob a supervisão eclesiástica. Foi sustentado pelo dinheiro oriundo de um engenho de sua propriedade, sito na ilha das Fontes, com casa de farinha e alambique de cachaça, o qual havia the valido a acusação de violar o voto de pobreza.

A principal alegação da defesa era a má vontade dos definidores, que se recusaram a considerar as testemunhas a favor do réu, e o cerceamento do direito de defesa ao apelante, o que foi reconhecido pelo Tribunal Ultramarino, que declarou a nulidade do julgamento. Baseado nisso, o prior geral, também absolveu o réu. Porém para conhecer estes detalhes do caso é preciso esperar até 1739 quando o caso é encerrado e vários documentos sobre o caso são transcritos. ${ }^{9}$

Antes disso, porém, com o recurso ao juízo régio, frei Manuel obteve a restituição do seu direito de voto e a suspensão da sentença, voltando ao seu convento em 1736. ${ }^{10} \mathrm{~A}$ volta de frei Manuel, ainda apoiada na liminar da justiça régia, deve ter instabilizado a vida do convento da Bahia. Seria muito interessante possuir fontes não oficiais a respeito, porém se não as temos, há muitos indícios nas Actas.

A sessão da volta de Madre de Deus foi das mais tumultuadas. Ele passou a exigir a presidência do capítulo para Baltasar de Figueiredo, pois o mesmo era mestre de Sacra Teologia. A Constituição da ordem atribuía este posto ao mestre mais antigo da província e, segundo Madre de Deus, essa determinação deveria ser interpretada como dando direito ao mestre de Teologia Baltasar de ser o primeiro definidor. A isso acrescenta frei Manuel que o próprio vice-rei, o conde das Galveias (que governou de 1735 até 1749), apoiava esta pretensão. O provincial entregou, então, a presidência, mas frei José Villasboas manifestou que iria recorrer ao prior geral da ordem na Itália e ditou a carta de protesto para que o secretário a lavrasse. Caetano Alberto Ossuna, senador da câmara da Bahia, advogado civil, foi então nomeado pelos padres para representá-los junto ao vice-rei para que a confusão fosse resolvida. ${ }^{11}$

Durante dez sessões do capítulo, nota-se, sob as formalidades das atas, a batalha entre os grupos de frei Manuel da Madre de Deus e de frei Boaventura da Conceição. As eleições e as nomeações vão favorecendo o primeiro. Como último golpe, aqueles que estão se vendo derrotados preparam uma questão jurídica.

Inácio de Santa Inês, durante a $11^{\text {a }}$. sessão do capítulo, indaga se os ex-vigários provinciais têm os mesmos direitos dos ex-provinciais quanto à precedência no definitório, o que significava na prática questionar se Manuel da Madre de Deus tinha direito ou não de participar das reuniões 
decisórias da ordem. Traz-se o livro antigo de atas, onde se lêem os decretos a respeito, anteriores à criação da província carmelita de Pernambuco e Bahia. Chega-se à conclusão que frei Manuel tem direitos de pertencer ao definitório. É então afastado frei Aleixo da Soledade, que o havia substituído durante os anos de sua ausência. A frei Aleixo resta apenas enviar um recurso ao superior da ordem a respeito. ${ }^{12}$

Em maio de 1737, na primeira sessão da primeira congregação intermediária os frades Félix de São João e Inácio de Santa Inês se opõem à presença de Manuel Barbosa como definidor perpétuo. Porém o mesmo foi aceito pelo definitório, sob o protesto dos dois e sob o risco de seu voto ser anulado quando da revisão pelo prior geral, o que nunca chegou a acontecer. A decisão do prior geral reforçou a posição de frei Manuel como legítimo definidor da província. Mesmo assim, em 1738, frei Manuel é afastado das reuniões deliberativas da província pelo provincial frei Raimundo Boim de Santo Antônio, que alega que não havia ainda definição da sacra congregação sobre seu caso. Além disso, "o reverendo padre prior mestre Maurício do Sacramento, primeiro definidor, também fez um protesto dizendo que o dito reverendo padre mestre Manuel da Madre de Deus era um perturbador da paz em que vivíamos". ${ }^{13}$ Só em 1739, sai o resultado do seu recurso, no qual frei Manuel é finalmente absolvido.

\section{A absolvição}

Para obter sua absolvição, o concubinato com a viúva Helena de Lima foi declarado falso. Alega-se que haveria apenas uma amizade entre os dois por causa do tio materno dela, o arcediago Manuel Fernandes Varzim. Outro ponto de contato entre os dois era o fato de que sua irmã, Francisca das Chagas, freira professa no convento do Desterro, era parente da mãe de Manuel da Madre de Deus. O depoimento de Helena sobre a questão foi essencial para esse desfecho. Quando ela tentou afirmar a existência da relação marital, Manuel provou com testemunhas que ela, na data do depoimento, era sua inimiga, tendo ficado

probatur multis testibus, quas produxit R. appellans in his actis, ipsam D. Helenam tempore quo tale juramentum praestitit, inimicam capitalem esse R. appellantis; item probatur ipsam juramentum praestitisse inductam ab inimicus ipsius appellantis, eo fine ut ipsium diffamarent et criminarentur, quod comprobatur ex eo quod cum non esse obligata eadem $D$. ad jurandum coram $R$. Judice a quo, hoc tamen

12 Actas, p.170-171

13 "R. P. MagisterMauritius a Sacramento 1 us Definitor etiam protestationem fecit dicens praedictum R. Patrem Magistrum Emmanuelem a Matre Dei esse perturbatorem pacis in qua eramus". Actas, p.182-184. 
voluntarie, et spontanee fecit, propriam confitens culpam quas ob causas in Jure fit inatendibile, et nullam tale juramentum ad probandam alienam culpam. ${ }^{14}$

A jogada jurídica da defesa, então, foi o princípio de que os co-réus não podem testemunhar um contra o outro, ou seja, quem admite a própria culpa não pode ser testemunha contra seu cúmplice. Ao admitir ser culpada de pecar contra os votos de castidade do frei, dona Helena se fez ré, e assim, não poderia acusar seu co-réu. Ainda mais suspeito se tornava o fato de a viúva ter jurado sem que um juramento lhe fosse exigido. Barroquismos legais estranhos, mas que ainda perduram em nosso direito.

O prior geral considerou que o lucro do engenho, herdado pelo religioso de sua avó dom Moniz de Almeida poderia ser usufruído pelo frei, como era costume em toda a América ("ex Jure illicitum non erat vendere productum ad ipsam fabricam conservandam, ut utuntur omnes alii Religiosi, qui similes fabricas habent in ista America"), ${ }^{15}$ mesmo porque a própria ordem herdaria mais tarde esse engenho e casa de farinha. Sobre os assassinatos, foi o frei absolvido pelo fato desses crimes nunca terem sido esclarecidos, jamais ficando provado, sequer, que Manuel de Brito e seu escravo tenham tido morte violenta. Manuel da Madre de Deus tinha sido indicado como mandante pelo criminoso Caetano de Brito, já condenado no Rio de Janeiro, mas este, quando interrogado, não conseguiu indicar o local exato onde teria enterrado os corpos dos supostos assassinados. ${ }^{16}$ Tudo foi atribuído, diante do tribunal régio, à malícia dos inimigos do frei:

Maxime cum R. adm. Judex a quo sit capitaliter infensus hostis R. Supplicantis, ut legaliter probatur per contextum omnium testium (...) cum R. adm. Judex a quo resquisivit testes (...) qui in Judicio saeculari juramentum praestiterunt $R$. appellantis, immo solum requisivit illum, qui juramentum contra illum praestiterunt quod fuit mala adeo voluntatem quod testes inhorabat, et minabatur illos, qui non deponent quomodo, et ipsi placebat, ut in facto proprio jurat testis Franciscus Xavierius Pimentel de Franca. ${ }^{17}$

Ao ser lida a certidão da sentença absolvitória em 24 de abril de 1739, não resta muito que fazer contra frei Manuel, a não ser medidas simbóli-

14 "provado por muitos testemunhos, que produziu o Réu apelante nestas atas, que esta Dona Helena no tempo em que tal juramento prestou, era inimiga capital do Réu apelante; assim foi provado que prestou esse juramento induzida pelos inimigos daquele apelante, com o fim de o difamar e incriminar, o que foi comprovado pelo fato de não ser obrigada a mesma Senhora a jurar diante do Reverendo Juiz a quo, mesmo assim espontânea e voluntariamente o fez, confessando a própria culpa, por causa disso, de Direito, foi inaceitável e nulo tal juramento para provar a culpa alheia". Actas, p.205

15 "de Direito, não era ilícito vender o produto deste engenho que ele conservava, como é costume de todos os outros Religiosos que têm engenhos semelhantes nesta América". Actas, p.206

16 Actas, p.207.

17 "Máxime quando o Reverendo ministro Juiz a quo seja o mais capital inimigo infenso do Réu Suplicante, o que foi provado legalmente pela concordância de todos os testemunhos (...) quando o Juiz a quo requisitou testemunhas que no juízo secular prestaram juramento sobre o Réu apelante, na verdade somente requisitou aqueles, que prestaram juramento contra ele, que foi de tão má vontade que ofendia as testemunhas e ameaçava aquelas que 
cas. Assim, a 7 de maio de 1740, durante a segunda sessão da primeira congregação intermediária, o ex-provincial Inácio de Santa Inês questiona a razão de Frei Manuel estar sentado em um dos lugares do primeiro lugar da congregação, se ele era apenas ex-vigário provincial e não ex-provincial. Como diz Molina, ${ }^{18}$ essas questões eram importantes para as pessoas do século XVIII, sendo prerrogativas como essas quase tão graves quanto questões de ordem econômica. Manuel defende seus direitos, simbólicos, dizendo que ali se assentava havia mais de vinte anos sem ter havido antes reclamação e que havia um decreto papal equiparando os vigários provinciais aos provinciais. Depois dessa discussão, foi feita a declaração da ordem em que deviam se assentar os presentes. ${ }^{19}$

A derrota do partido contrário a frei Manuel se completa com a condenação e exílio de frei Boaventura da Conceição e do ex-provincial Manuel Ângelo de Almeida. Segundo a ordem:

Senhor Prior Provincial dos Religiosos Carmelitas Calçados da Provincia da Bahia. Sua Magestade por justos motivos he servido, que V. Paternidade Rma. na primeyra embarcação que houver, mande para dous Conventos dos mais remotos, e distantes dessa Cidade ao ExProvincial Fr. Manuel Angelo de Almeyda, e ao ExPrior Fr. Boaventura da Conceyção, e logoque chegarem aquelle, que cada hum respectivamente for destinado, dos quaes não poderão ser mudados para outros sem nova ordem do mesmo Senhor, mandarão certidões seos Prelados. ${ }^{20}$

Quais os "justos motivos" de Sua Majestade, não nos é dado a saber nesta verdadeira lettre de cachet. Esse instrumento legal, característico dos regimes absolutistas, em que o próprio rei interfere para evitar o alarido e o escândalo, oculta seus motivos para evitar a desonra e o publicidade do que a moral mandava esconder. ${ }^{21}$

Os partidários de Madre de Deus, com esta vitória final, conseguem se eleger para as principais funções da província e, a 22 de abril de 1741, durante a primeira sessão da segunda congregação intermediária a eleição do definitório anterior é anulada, sendo escolhido pelos confrades, Francisco Xavier da Trindade para substituir Manuel Barboza. Ipso facto, o definitório vai se reunir na cela de Manuel da Madre de Deus. Agora é a vez de frei Francisco de Inácio de Santa Inês refugiar-se no convento de São Bento (Actas, p.236-239).22

não depunham como lhe agradava, como sobre o próprio caso jurou a testemunha Francisco Xavier Pimentel da França". Actas, p.208.

18 MOLINA, Sandra Rita. Na dança dos Altares: a ordem do Carmo e a irmandade da Boa Morte entre o poder e a sobrevivência no Rio de Janeiro dos primeiros anos do Império (1814-1826), p.112.

19 Actas, p.227-228.

20 Actas, p.233-234.

21 Cf. FARGE, Arlette. Famílias: a honra e o sigilo. In: ARIĖS, Philippe e DUBY, Georges. (orgs.) História da vida privada 3: da renascença ao século das luzes. São Paulo: Companhia das Letras, 2006, p.581.

22 Actas, p.241-246. 
A 13 de abril de 1742, a primeira sessão do capítulo é presidida por Manuel da Madre de Deus. Como frei Francisco Xavier da Trindade não pôde assumir o cargo de primeiro definidor por problemas burocráticos, Manuel da Madre de Deus passou a presidir o capítulo por ser o mais antigo dos mestres da província. Este, então, nomeia Frei André Leitão secretário do capítulo. Por ordem do rei, frei Boaventura da Conceição, ex-prior dos conventos de Cachoeira, Sergipe e da Bahia, fora exilado para Olinda e Manuel Ângelo de Almeida no Cabo de Santo Agostinho. Frei Inácio de Santa Inês continuava fugido. Depois deste triunfo final de Madre de Deus, as atas calam sobre sua pessoa.

\section{Conclusão}

Neste trabalho verificamos a íntima ligação entre estado, religião e propriedade no Brasil colonial. Como diz Sonia Siqueira, ${ }^{23}$ a religião na Bahia colonial associava-se à ordem privada e os próprios clérigos não concebiam a vida religiosa em separado dos seus interesses pessoais.

Frei Manuel surge nesse processo como uma pessoa pública, porém carregada de individualidade, em meio a um turbilhão de rixas pessoais, vaidades, fraquezas humanas e politicagens. Ele e seus confrades parecem preocupados em salvar a pele e, se possível, promover-se, gozando uma vida o mais prazerosa possível, enquanto provocam "estragos" na tranqüilidade e influência dos seus inimigos pessoais. Não se comportam como membros de uma grande categoria sociológica preocupados em movimentar suas engrenagens, ou manifestar suas características e contradições, embora seja isso que estejam fazendo.

Seria interessante verificar por outras fontes, se as houver, as razões do Estado português em se imiscuir nas questões claustrais desse caso específico e qual a dimensão pública que o caso atingiu na época, desvelando a rede de intrigas que os indícios das atas capitulares só nos deixam entrever.

23 SIQUEIRA, Sonia. O pecado na Bahia nos séculos XVI e XVII. Anais do IV Congresso de História da Bahia. Salvador: Instituto Histórico e Geográfico da Bahia/Fundação Gregório de Matos, v.l, p.155, 2001. 